Article

\title{
Comparison of Different Missing-Imputation Methods for MAIAC (Multiangle Implementation of Atmospheric Correction) AOD in Estimating Daily PM2.5 Levels $_{2}$
}

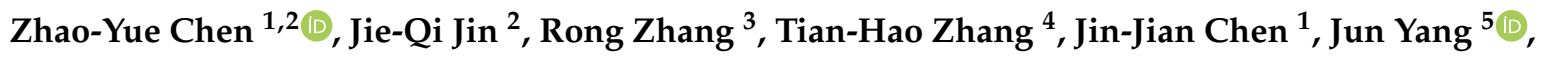 \\ Chun-Quan $\mathrm{Ou}^{2, *}$ ) and Yuming Guo ${ }^{1}$ \\ 1 Department of Epidemiology and Preventive Medicine, School of Public Health and Preventive Medicine, \\ Melbourne, VIC 3004, Australia; zhaoyue21@i.smu.edu.cn (Z.-Y.C.); cjj19960824@i.smu.edu.cn (J.-J.C.); \\ yuming.guo@monash.edu (Y.G.) \\ 2 State Key Laboratory of Organ Failure Research, Department of Biostatistics, Guangdong Provincial Key \\ Laboratory of Tropical Disease Research, School of Public Health, Southern Medical University, \\ Guangzhou 510515, China; jjq123@i.smu.edu.cn \\ 3 Department of Urban Planning and Design, The University of Hong Kong, Pokfulam, Hong Kong; \\ rong.zhang@connect.hku.hk \\ 4 State Key Laboratory of Information Engineering in Surveying, Mapping and Remote Sensing, \\ Wuhan University, Wuhan 430079, China; tianhaozhang@whu.edu.cn \\ 5 Institute for Environmental and Climate Research, Jinan University, Guangzhou 511443, China; \\ yangjun_eci@jnu.edu.cn \\ * Correspondence: ocq@smu.edu.cn; Tel.: +8620-61360456; Fax: +8620-61648319
}

Received: 25 July 2020; Accepted: 14 September 2020; Published: 15 September 2020

\begin{abstract}
The immense problem of missing satellite aerosol retrievals (Aerosol Optical Depth, (AOD)) detrimentally affects the prediction ability of ground-level $\mathrm{PM}_{2.5}$ concentrations and may lead to unavoidable biases. An appropriate missing-imputation method has not been well developed to date. This study developed a two-stage approach (AOD-imputation stage and $\mathrm{PM}_{2.5}$-prediction stage) to predict short-term $\mathrm{PM}_{2.5}$ exposure in mainland China from 2013-2018. At the AOD-imputation stage, geostatistical methods and machine learning (ML) algorithms were examined to interpolate $1 \mathrm{~km}$ satellite aerosol retrievals. At the $\mathrm{PM}_{2.5}$-prediction stage, the daily levels of $\mathrm{PM}_{2.5}$ were predicted at a resolution of $1 \mathrm{~km}$, based on interpolated AOD and meteorological data. The statistical performances of the different interpolation methods were comprehensively compared at each stage. The original coverage of retrieved AOD was $15.46 \%$ on average. For the AOD-imputation stage, ML methods produced a higher coverage (98.64\%) of AOD than geostatistical methods (21.43-87.31\%). Among ML algorithms, random forest (RF) or extreme gradient boosted (XG-interpolated) AOD produced better interpolated quality $\left(\mathrm{CV} \mathrm{R}^{2}=0.89\right.$ and 0.85$)$ than other algorithms $(0.49-0.78)$, but XGBoost required only $15 \%$ of the computing time of RF. For the $\mathrm{PM}_{2.5}$ predicted stage, neither RF-AOD nor XG-AOD could guarantee higher accuracy in $\mathrm{PM}_{2.5}$ estimations ( $C V \mathrm{R}^{2}=0.88$ (RF or XG-AOD) compared to 0.85 (original)), or more stable spatial and temporal extrapolation (spatial, (temporal) $\mathrm{CV} \mathrm{R}^{2}=0.83(0.83)$, $0.82(0.82)$, and 0.65 (0.61) for RF, XG, and original). For the AOD-imputation stage, the missing-filled efficiency depended more on external information, while the missing-filled accuracy relied more on model structure. For the $\mathrm{PM}_{2.5}$ predicted stage, efficient AOD interpolation (or the ability to eliminate the missing data) was a precondition for the stable spatial and temporal extrapolation, while the quality of interpolated AOD showed less significant improvements. It was found that XG-AOD is a better choice to estimate daily $\mathrm{PM}_{2.5}$ exposure in health assessments.
\end{abstract}

Keywords: machine learning; aerosol optical depth; missing replacement; short-term; $\mathrm{PM}_{2.5}$ 


\section{Introduction}

Since 1998, in China and India, industrialization, economic development, and a substantially increasing energy demand has led to over five times and triple growth in China's and India's coal-fired power, respectively [1]. Although accounting for $36 \%$ of the world's population, they have accounted for $59 \%$ of global disease burden attributable to fine-particulate pollution [2]. Many previous epidemiological studies around the world have linked short-term $\mathrm{PM}_{2.5}$ exposure to emergency hospital admissions and even deaths from acute or chronic illnesses such as asthma and stoke [3-7]. Despite such severe air pollution conditions and widely publicized concerns, there are sparse PM monitoring stations, and this is a significant hurdle for assessing pollution exposure. Among the 7.5 billion people worldwide, only approximately 5.9 billion (approximately $80 \%$ ) people live in regions that are covered by available PM readings [8]. This is because of the high cost of building and maintaining monitoring sites.

In recent years, there has been an increasing trend to use satellite aerosol optical depth (AOD) for estimating ground-level $\mathrm{PM}_{2.5}$ concentrations. Compared with conventional monitoring, the lower cost, higher coverage, and higher spatial resolution are advantageous, but the inherent drawbacks of AOD are obvious and difficult to solve. The most critical issue is the high missing rate of satellite-retrieved AOD, potentially related to orbit patterns, cloudiness, polar night, and surface reflectivity $[9,10]$. Kahn et al. [10] reported that the fairly low likelihood (approximately 15\%) of successfully extracting aerosol retrievals from satellite instruments is a global problem, and the high missing rate of aerosol retrievals makes it impossible to estimate short-term $\mathrm{PM}_{2.5}$ exposure in continuous time series or most time in the research period [11-13]. Furthermore, some reported daily $\mathrm{PM}_{2.5}$ measurements have presented different distributions between AOD-missing days and other days [14]. Compared with long-term pollution exposure, short-term health assessments rely more on integral temporal variations in exposure. A drawback of satellite-based estimates is that they cannot represent the real distribution of $\mathrm{PM}_{2.5}$.

For addressing this issue, AOD retrievals need to be imputed before estimating $\mathrm{PM}_{2.5}$ levels where AOD is an important input variable. Multiple geostatistical approaches have attempted to impute AOD. Some examples are inverse distance weighting, nearest neighbors, kriging, generalized additive models or multiple imputation [15-17], but have achieved relatively low efficiency (missing rate after interpolation approximately $30-50 \%$ ) and quality (cross-validation R-square approximately 0.34-0.64). We previously proposed [8] a two-step (TS) interpolation (first using data from Terra to estimate Aqua missing values, then inverse distance weighted interpolation (IDW) for second step) to reduce the AOD-missing rates from $87.91 \%$ to $13.83 \%$, and maintain a relatively satisfactory performance $(\mathrm{CV}$ R-square $=0.76)$. However, the coverage needs to be increased further, and higher efficiency of interpolations were also required, especially when the sample size increased with a higher resolution in (Multiangle Implementation of Atmospheric Correction) MAIAC AOD ( $3^{2}$ times with resolution from $3 \mathrm{~km}$ to $1 \mathrm{~km}$ ). Moreover, our previous method [9] was over-dependent on geostatistical interpolation and ignored some influences of other external information such as meteorological data and cloud fraction on the temporal dimension, which inevitably weakened the efficiency and accuracy of imputation. This study endeavors to improve upon some weaknesses in the previous study. Machine learning methods can assist with solving these problems due to their strengths in capturing complex non-linear relationships and high dimension interactions $[9,18]$. We attempted to select an optimal method by comprehensively comparing a variety of machine learning algorithms and geostatistical approaches in imputing missing data of AOD.

After imputing missing data of AOD, we previously confirmed that the combined method of non-linear exposure-lag-response model (NELRM) and XGBoost is superior to other nine ML models at a large spatial scale $\left(\mathrm{CV} \mathrm{R}^{2}=0.86\right.$ vs. $\left.0.54 \sim 0.83\right)$ [9], but it is still unknown how different AOD-imputation methods will affect the accuracy of $\mathrm{PM}_{2.5}$ predictions. 
Using a 6-year MAIAC AOD with a resolution of $1 \mathrm{~km}$, this study aimed to compare the statistical performance of different geostatistical and machine learning (ML) algorithms at the AOD-imputation stage and also assess the influence of different imputation methods on the $\mathrm{PM}_{2.5}$-prediction stage.

\section{Materials and Methods}

\subsection{Materials}

\subsubsection{Satellite-Retrieved Product}

A $1 \mathrm{~km}$ aerosol product covering China from 2013-2018 was acquired from the NASA Multiangle Implementation of Atmospheric Correction (MAIAC) AOD (https:/ladsweb.modaps.eosdis.nasa. gov/) $[19,20]$. Compared with traditional retrieving algorithms, MAIAC can retrieve finer resolution aerosol data from the Moderate Resolution Imaging Spectro radiometer (MODIS) Collection 6 (C6) [20-22], and can improve AOD correction during cloud and snow, which is the vulnerable detection moment of a remote sensor [20]. Only the extracted AOD with a quality assurance flag will be used [21-23]. In addition, a 16-day $1 \mathrm{~km}$ Enhanced Vegetation Index (EVI) product and MODIS daily 5-km cloud fraction data (MOD06_L2) were obtained from the NASA website.

\subsubsection{Daily Monitoring Data}

Daily site-level $\mathrm{PM}_{2.5}$ measurements, collected by the tapered-element oscillating microbalance method (China MEE, 2016) in mainland China during 2014-2018 were obtained from the China National Environmental Monitoring Center. The start time of the study period was 2014 because the national $\mathrm{PM}_{2.5}$ monitoring system was built in 2014 [9,24,25]. A total of 1605 monitoring sites in 385 cities are shown in Figure S1A.

\subsubsection{Meteorological Data and Land-Cover Data}

Meteorological data, including the daily mean temperature, pressure, sunshine hours, water vapor pressure, precipitation, relative humidity, wind speed, and wind direction, were obtained from 839 meteorological stations (Figure S1B) during 2013-2018. For further integration, the Universal Kriging (UK) technique was employed to interpolate the daily site-level meteorological data into grid cells with a resolution of $1 \mathrm{~km}$. The 6-hour planetary boundary layer height (PBLH) from the National Centers for Environmental Prediction (NECP) was daily averaged and resampled from 1 degree to $1 \mathrm{~km}$ grid cells [9].

\subsection{Methodology}

The general workflow for estimating daily $\mathrm{PM}_{2.5}$ exposure (including AOD-imputation stage and $\mathrm{PM}_{2.5}$-prediction stage) is demonstrated in Figure 1. 


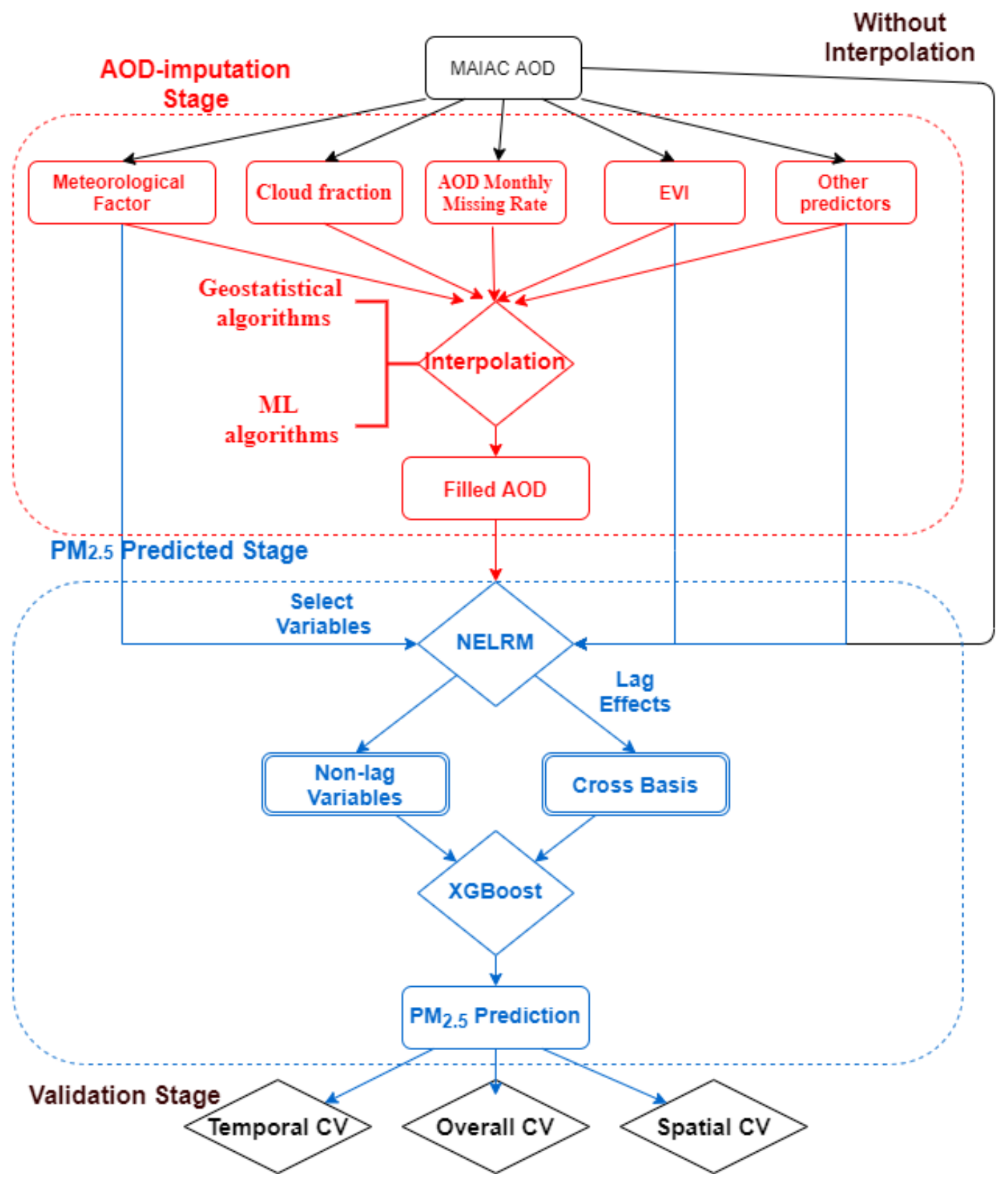

Figure 1. Framework for short-term $\mathrm{PM}_{2.5}$ exposure estimation.

\subsubsection{AOD-Imputation Stage for MAIAC AOD}

To select the optimal missing-filled methods for MAIAC AOD, we compared all potential methods, if the data required were available. These included different geostatistical interpolations [26-28], two-step imputation previously proposed [9] and other ML interpolating methods, including random forest (RF) [29], XGBoost (extreme gradient boosting) [30], support vector machine (SVM) [31], gradient boost model (GBM) [32], generalized additive model (GAM) [33], Bayesian regularized neural network (BRNN) [34], and least absolute shrinkage and selection operator (LASSO) [35]. The interpolation methods are summarized in Table 1. In general, geostatistical algorithms mainly depend on using spatial and temporal information in existing AOD data, while ML algorithms mainly use the complex relationship between AOD and other external information. 
Table 1. Summary table of different interpolation methods at the AOD-imputation stage.

\begin{tabular}{|c|c|c|c|}
\hline Methods & Main Features & Merits & Demerits \\
\hline \multicolumn{4}{|c|}{ Geostatistical Algorithms } \\
\hline TS [9] & $\begin{array}{l}\text { step I: mixed effect model } \\
\text { Step II: IDW }\end{array}$ & using different satellite products & more steps \\
\hline ST Kriging [28] & $\begin{array}{l}\text { regionalize spatio-temporal variable to obtain } \\
\text { semi-variance for kriging }\end{array}$ & $\begin{array}{l}\text { maximize use } \\
\text { spatio-temporal neighborhood } \\
\quad \text { information }\end{array}$ & $\begin{array}{l}\text { extensive computation for large } \\
\text { spatial and temporal scale }\end{array}$ \\
\hline IDW [28] & $\begin{array}{l}\text { inversed distance weighted-average within } \\
\text { search radius }\end{array}$ & easier and quicker to calculated & $\begin{array}{l}\text { less accurate for } \\
\text { complex spatial distribution }\end{array}$ \\
\hline Kriging [28] & $\begin{array}{l}\text { using semi-variance to explore spatial } \\
\text { distribution within search radius }\end{array}$ & commonly used & not considering temporal variation \\
\hline NN [28] & nearest neighbors within search radius & easiest and quickest to calculate & less spatial variation \\
\hline \multicolumn{4}{|c|}{ Machine Learning Algorithms } \\
\hline LASSO [35] & $\begin{array}{l}\text { L1 regularization term was used to penalize } \\
\text { nonessential or correlated features in model }\end{array}$ & $\begin{array}{l}\text { prevent over fitting and ensure } \\
\text { generalization }\end{array}$ & $\begin{array}{c}\text { difficult to capture complex } \\
\text { non-linear or interacting relationship }\end{array}$ \\
\hline GAM [33] & use smooth functions to describe the relationship & fit non-linear relationship & easier to over fit \\
\hline GBM [32] & $\begin{array}{c}\text { an ensemble of weak prediction models, such as } \\
\text { decision trees. }\end{array}$ & $\begin{array}{c}\text { optimized by negative gradient of loss } \\
\text { function. }\end{array}$ & $\begin{array}{l}\text { over fitting and more computation } \\
\text { time }\end{array}$ \\
\hline BRNN [34] & $\begin{array}{l}\text { Bayesian Inference was used to regularize the } \\
\text { Maximum Likelihood in Neural Nets } \\
\text { (similar regularization in Ridge Regression) }\end{array}$ & $\begin{array}{l}\text { more robust than standard } \\
\text { back-propagation nets }\end{array}$ & $\begin{array}{l}\text { higher computation than } \mathrm{L} 1 \\
\text { regularization }\end{array}$ \\
\hline SVM [31] & $\begin{array}{l}\text { Using kernel to map data into higher dimension, } \\
\text { and then to fit the error within a certain threshold }\end{array}$ & $\begin{array}{l}\text { produces higher accuracy with less } \\
\text { computation power }\end{array}$ & $\begin{array}{l}\text { weaker extrapolating ability in data } \\
\text { with more noise }\end{array}$ \\
\hline RF [29] & $\begin{array}{l}\text { a meta estimator with numbers of classifying } \\
\text { decision trees based on different sub-samples }\end{array}$ & control the overfitting by sub-samples & more computation time \\
\hline XG [30] & $\begin{array}{l}\text { a weighted ensemble of weak prediction models } \\
\text { with regularized boosting and parallel processing }\end{array}$ & $\begin{array}{l}\text { regularized boosting and parallel } \\
\text { processing }\end{array}$ & less stable results in early stopping \\
\hline \multicolumn{4}{|c|}{$\begin{array}{l}\text { TS (two-step interpolation), ST Kriging (spatio-temporal kriging with } 50 \mathrm{~km} \text { buffer), IDW (inverse distance } \\
\text { weighting with } 50 \mathrm{~km} \text { buffer), NN (nearest neighbors with } 30 \mathrm{~km} \text { buffer), LASSO (Least absolute shrinkage and } \\
\text { selection operator), GAM (generalized additive model), GBM (gradient boost model), BRNN (Bayesian regularized } \\
\text { neural network), SVM (support vector machine), RF (conditional inference random forest), and XG (extreme } \\
\text { gradient boosting). }\end{array}$} \\
\hline
\end{tabular}

Geostatistical algorithms require less information and can suit the situation without requiring external information. In most cases, ML algorithms can provide a model for an entire study period, but geostatistical algorithms need to be conducted separately for each day or at specified intervals because they cannot provide a fixed model for the entire period. The parameter setting used in this study (Table S1) was tuning by 10 -fold cross-validation.

For the ML algorithms, the selected predictors among different ML methods remained consistent to compare their performances objectively. All external information was selected by linear models with statistical significance $(\mathrm{P}<0.05)$ and low variance inflation ( $\mathrm{VIF}<5$, checks for multi-collinearity). The external information included PBLH, maximum ground surface temperature (Maxgst), precipitation (rain), maximum atmospheric pressure (Maxpres), mean relative humidity (MeanRH), sunshine duration (sunshine), mean ambient temperature (Meantemp), max/maximum wind speed (WS/MWS), cloud fraction (representing the levels of cloud coverage) from MOD06_L2, AOD monthly missing rate, EVI, and indicator variables such as longitude and latitude, altitude, day of the year, month, year, and day of the week. It should be noted that the sample size of MAIAC AOD covering China from 2013-2018 was too large (approximately 96,534,23 (numbers of grids) $\times 365$ (days) $\times 6$ (years)) to train the missing-filled model, and therefore, 5000 grids were randomly selected for each day as the modeling data (total sample size $=5000$ (numbers of grids) $\times 365$ (days) $\times 6$ (years)). The external information for each grid was extracted from the corresponding grid cell.

\subsection{2. $\mathrm{PM}_{2.5}$-Prediction Stage}

Due to natural geographical differences among the seven geographical regions in China such as climate, terrain, and vegetation [9], a satellite- $\mathrm{PM}_{2.5}$ model was constructed separately for each region. To alleviate the discontinued and less-certainty problem between the regions' boundaries, the sites in the neighboring province (Figure S2) were also included in the corresponding modeling region.

Our previous $\mathrm{PM}_{2.5}$ prediction model (a combined method of NELRM and XGBoost) [9] worked well at a large spatial scale $\left(C V R^{2}=0.86\right)$ compared with other ML models (including random forest), and therefore, this study retained a similar $\mathrm{PM}_{2.5}$ model structure. Here, the impacts of 
different interpolations at the AOD-imputation stage on $\mathrm{PM}_{2.5}$ predictive accuracy are mainly explored, rather than improving $\mathrm{PM}_{2.5}$ model structure. The steps of the NELRM-XGBoost model have been previously described [9] and will be introduced briefly. First, non-lagged variables $X_{1}$ such as land-related data, and potential lagged variables $X_{2}$ such as original AOD, and meteorological variables were selected in the NELRM [14], with statistical significance $(P<0.05)$ and low variance inflation ( $\mathrm{VIF}<5$, checks for multi-collinearity). The optimal predictor combinations in different regions are shown in Table S2). Additionally, a cross-basis Cb. $X_{2}$ was constructed, explaining the lag effects, with degree of freedom $(\mathrm{df}=3)$ for natural cubic smooth function and maximum 0-1 lagged days according to the 10-fold CV results. Finally, the weak learner $f_{k}\left(X_{1}, C b . X_{2}\right)$ in XGBoost learning process was built, which was optimized by the loss function $\mathrm{L}^{k}\left(\theta_{k}\right)$, adjusted by a previous iteration, and the regularizing term $\Omega^{k}\left(\theta_{k}\right)$, and hence, reducing model complexity for avoiding over fit. This is presented as the following equation:

$$
\hat{y}_{i}^{(t)}=\sum_{k=1}^{t} \varepsilon \gamma_{k} f_{k}\left(X_{1}, C b . X_{2}\right)
$$

where $\hat{Y}_{i}^{(t)}$ denotes $\mathrm{PM}_{2.5}$ estimation in iteration $\mathrm{t} ; \gamma_{k}$ and $\varepsilon$ are the weight vector and the learning rate. The setting in the satellite-PM $\mathrm{PM}_{2.5}$ model (Table S1) was optimized by maximizing the 10 -fold CV $\mathrm{R}^{2}$ of the XGBoost approach for estimating $\mathrm{PM}_{2.5}$.

\subsubsection{Validation Stage}

To better validate the performance of two stages, three kinds of 10-fold CV [14], were deployed, including overall CV, spatial CV, and temporal CV. All 10-fold CV were repeated 20 times. The main difference among them was randomly separating the dataset by observations, the location of sites, and date.

The overall CV is a common measurement that represents the performance stability in modeling dataset [13,23,36-38].

Spatial CV or spatial extrapolation is a more important indicator of prediction model of $\mathrm{PM}_{2.5}$, because most predicted locations for exposure assessment do not have any observation due to the limited numbers of sites (1605). For a better description of the spatial performance distribution, we also conducted a Leave-One-Out-Cross-Validation $\left(\mathrm{LOOCV}_{\text {site }}\right)$, which leaves one site for validation each time. The LOOCV $\mathrm{Lite}_{\text {sim }}$ results were further interpolated by UK into $1 \mathrm{~km}$ grids in China (interpolating quality: $\left.C V \mathrm{R}^{2}=0.86\right)$, which simply represents spatial extrapolation in different predicted locations.

The temporal CV, or temporal extrapolation means the performance stability in different time points, as the training and validating datasets randomly split by dates in each fold. Furthermore, the validation analysis was performed in different months or years to examine the performance stability (Figure S3).

\section{Results}

\subsection{Descriptive Statistics of MAIAC AOD and $P M_{2.5}$ Concentration}

From 2013 to 2018, the daily coverage of MAIAC AOD in China generally remained at an average of approximately 15-16\% (Figure 2). The highest coverage day was on 9 October 2013, reaching 33.22\%, and the lowest coverage day was $4.55 \%$ on 3 July 2018. June-July and January-February accounted for $42.24 \%$ and $28.87 \%$ of the lower-coverage ( $\leq 10 \%$ ) days, respectively, and more than $62.31 \%$ of the higher-coverage $(\geq 20 \%)$ days were from September-December. The median value of the observed MAIAC AOD during the study period was approximately 0.31(interquartile range (IQR): 0.34).

From 2014 to 2018 , the median $\mathrm{PM}_{2.5}$ concentrations reported by the monitoring sites gradually decreased from $45.60 \mu \mathrm{g} / \mathrm{m}^{3}(\mathrm{IQR}=43.89)$ to $32.14 \mu \mathrm{g} / \mathrm{m}^{3}(\mathrm{IQR}=30.34)$. The $\mathrm{PM}_{2.5}$ concentrations in China were always higher in the cold season (October-March). 


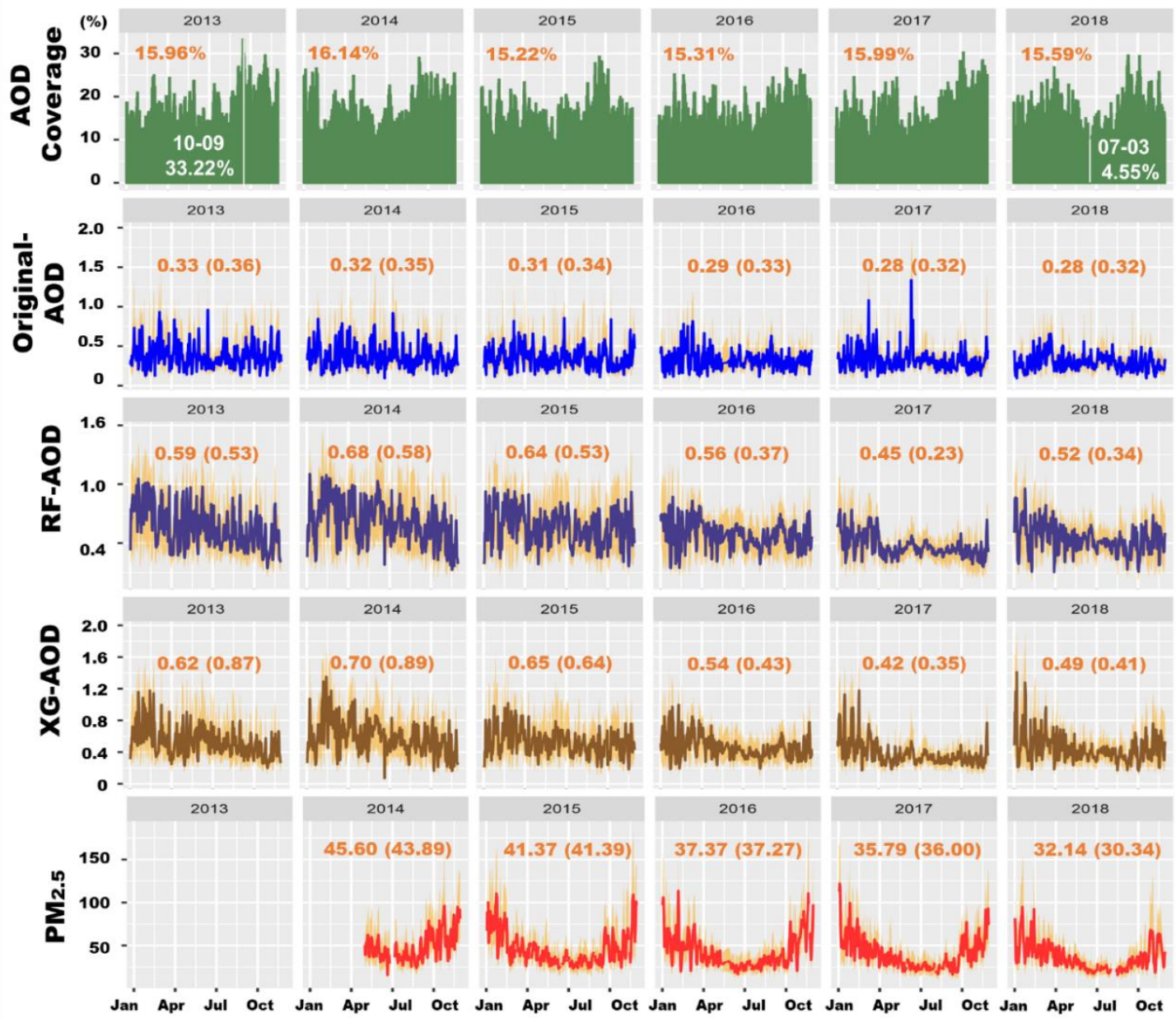

Figure 2. Descriptive statistics (coverage (\%) and median (IQR)) of MAIAC AOD product, interpolated AOD, and observed ground-level $\mathrm{PM}_{2.5}$ concentrations.

\subsection{AOD-Imputation Stage}

Compared with the geostatistical interpolation methods (coverage after interpolation approximately $21.43-87.31 \%$ for NN, Kriging, IDW, ST Kriging, and TS) (Table 2), the ML methods, using the same external information, were more efficient in filling the gaps, with almost full coverage (approximately $98.64 \%$ ). The remaining missing data could not be fully eliminated due to the missing rates of external information. Among these algorithms, the RF and XG methods outperformed other algorithms $\left(\mathrm{CV} \mathrm{R}^{2}=0.89,0.85\right.$, and $0.49-0.78$ for $\mathrm{RF}, \mathrm{XG}$, and other algorithms, respectively). Although the RF method was the most accurate, its computation time was longer than other ML algorithms and most geostatistical algorithms. The XG method was less time-consuming, had better performance, and higher coverage than our previous TS methods, although the accuracy was slightly lower than RF. Similar results were obtained for spatial CV and temporal CV (Table S3). Among the interpolations with higher accuracy $\left(\mathrm{CV} \mathrm{R}^{2} \geq 0.7\right)$, we found the median AOD level always tended to increase (from 0.31 to $0.44-0.65$ ) after geostatistical or ML interpolation. Owing to the same coverage in ML-interpolated AOD product (same external information for all ML algorithms), they had a more similar interpolated AOD distribution than the geostatistical interpolation. In addition, the linear correlation between interpolated $\mathrm{AOD}$ and $\mathrm{PM}_{2.5}$ weakened after the interpolation (Table S4). 
Table 2. Comparison of geostatistical and machine learning (ML) interpolation for MAIAC AOD product.

\begin{tabular}{|c|c|c|c|c|c|}
\hline Interpolation Method & Coverage $(\%)$ & $\begin{array}{c}\text { Computation } \\
\text { Time }^{\mathrm{a}}\end{array}$ & CV RMSE & $\mathrm{CV} \mathrm{R} \mathrm{R}^{2}$ & CV MAPE (\%) \\
\hline Before Interpolation & \multicolumn{2}{|c|}{15.46} & \multicolumn{3}{|c|}{1} \\
\hline \multicolumn{6}{|c|}{ Geostatistical Algorithms } \\
\hline TS & 87.31 & $55: 38: 56.56$ & 0.17 & 0.75 & 20.56 \\
\hline ST Kriging & 67.73 & $128: 56: 43.56$ & 0.17 & 0.78 & 20.36 \\
\hline IDW & 45.22 & $45: 35: 28.39$ & 0.18 & 0.65 & 21.35 \\
\hline Kriging & 42.37 & $88: 46: 37.24$ & 0.17 & 0.66 & 20.89 \\
\hline NN & 21.43 & $15: 39: 27.93$ & 0.19 & 0.49 & 25.38 \\
\hline \multicolumn{6}{|c|}{ ML Algorithms } \\
\hline RF & 98.64 & $120: 55: 28.65$ & 0.15 & 0.89 & 18.00 \\
\hline XG & 98.64 & 18:00:38.20 & 0.15 & 0.85 & 19.06 \\
\hline SVM & 98.64 & 19:04:47.64 & 0.17 & 0.72 & 19.41 \\
\hline BRNN & 98.64 & $18: 45: 36.22$ & 0.17 & 0.70 & 22.39 \\
\hline GBM & 98.64 & 06:35:47.65 & 0.18 & 0.69 & 25.17 \\
\hline GAM & 98.64 & 01:05:38.20 & 0.17 & 0.62 & 21.88 \\
\hline LASSO & 98.64 & 01:18:30.23 & 0.19 & 0.49 & 28.03 \\
\hline $\begin{array}{l}\text { TS (two-step interpolation } \\
\text { neighbors with } 30 \mathrm{~km} \text { buff } \\
\text { SVM (support vector mac } \\
\text { (generalized additive mod } \\
\text { system in } 3.4 \mathrm{GHz} \text { compu }\end{array}$ & $\begin{array}{l}\text { IDW (inverse dis } \\
\text { RF (Conditiona } \\
\text { e), BRNN (Bayes } \\
\text { and LASSO (lea } \\
\text { with } 16 \text { GB of R }\end{array}$ & $\begin{array}{l}\text { nce weighting), } S \\
\text { ference Random } \\
\text { n regularized neu } \\
\text { absolute shrinką } \\
\text { M. }\end{array}$ & $\begin{array}{l}\text { Kriging (spat } \\
\text { orest), XG (ext } \\
1 \text { network), G } \\
\text { and selection }\end{array}$ & $\begin{array}{l}\text { emporal k } \\
\text { le gradien } \\
\text { [ (gradien } \\
\text { erator); }{ }^{a} \mathrm{t}\end{array}$ & $\begin{array}{l}\text { ging), NN (nearest } \\
\text { oosting, XGBoost), } \\
\text { oost model), GAM } \\
\text { ed by Windows } 10\end{array}$ \\
\hline
\end{tabular}

\section{3. $P M_{2.5}$ Predicted Stage}

Six AOD-interpolation methods allowed relatively higher performances (with $C V \mathrm{R}^{2}$ after over 0.7 ), and therefore, their interpolated AOD product was used to build the daily $\mathrm{PM}_{2.5}$ prediction model at the second stage (CV R $\mathrm{R}^{2}: 0.83-0.88$ ) (Table S5). It was found that using AOD products interpolated by XG or RF (XG-AOD or RF-AOD) was beneficial to short-term $\mathrm{PM}_{2.5}$ prediction accuracy (CV R ${ }^{2}$ : both 0.88 ), and more accurate than when using original AOD data (CV R $\left.\mathrm{R}^{2}: 0.85\right)$. We, therefore, further compared XG-AOD and RF-AOD in different regions (Figure 3). Generally, $\mathrm{PM}_{2.5}$ prediction models using either AOD product performed similarly and obtained CV $\mathrm{R}^{2}$ higher than 0.88 in most regions of China, except for the northwest (approximately 0.77-0.78). Using XG-AOD was more stable (lower SD or narrower $95 \% \mathrm{CI}$ for $\mathrm{CV} \mathrm{R}^{2}$ ) in the northwest. This was similar to spatial CV and temporal CV (spatial (temporal) $C V \mathrm{R}^{2}=0.83(0.83)$ for RF vs. 0.82(0.82) for $\mathrm{XG}$ ), while the $\mathrm{PM}_{2.5}$ prediction model using the original AOD had a less stable performance, with a spatial CV $\mathrm{R}^{2}$ of 0.65 and a temporal CV $\mathrm{R}^{2}$ of 0.61 (Table S6).

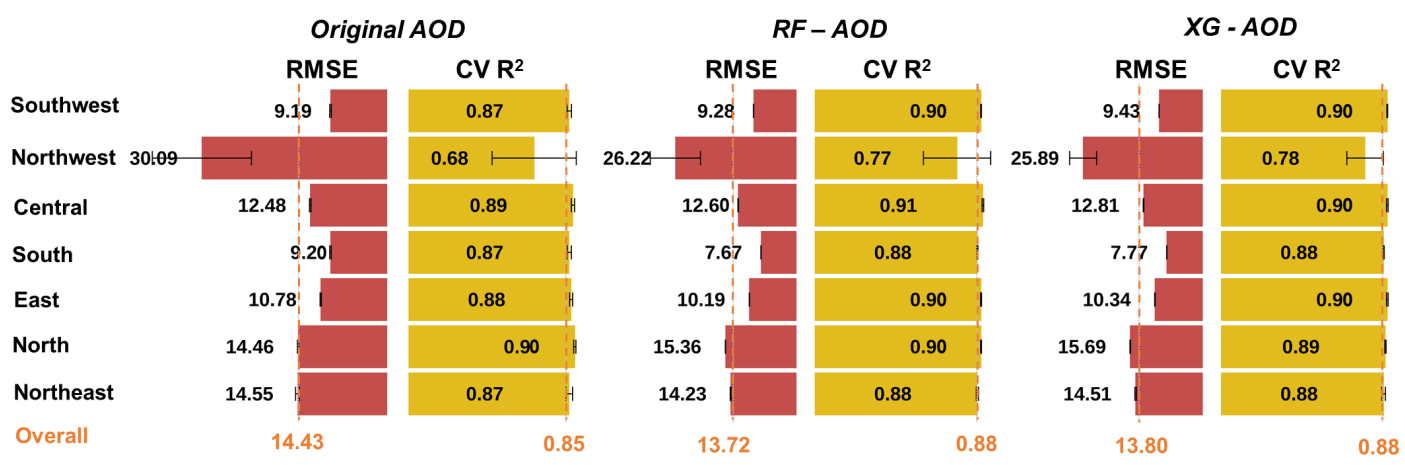

Figure 3. Cross-validation performance of $\mathrm{PM}_{2.5}$ prediction model with AOD products interpolated by using random forest $(\mathrm{RF})$ and extreme gradient boosting $(\mathrm{XG})$. Orange dashed line: the overall performance; error bar: $95 \%$ CI. 


\subsection{Spatial and Temporal Cross-Validation}

Due to the high demand of spatial extrapolation, a LOOCV site analysis was conducted (Figure 4). The results were similar while using two different interpolated AOD products at the $\mathrm{PM}_{2.5}$-prediction stage. The model using RF-AOD performed slightly better than XG-AOD (median LOOCV R ${ }^{2}$ (RMSE): $0.81\left(14.68 \mu \mathrm{g} / \mathrm{m}^{3}\right)$ vs. $0.78\left(15.07 \mu \mathrm{g} / \mathrm{m}^{3}\right)$, respectively). Both were significantly better than using original AOD (median LOOCV $R^{2}=0.56$, RMSE $=24.48 \mu \mathrm{g} / \mathrm{m}^{3}$ ). The grids with higher accuracy (coverage rate and LOOCV $\mathrm{R}^{2}>$ median level) were mainly located in the east of China, including Central, South, East, North, and Northeast China. For temporal CV, the RF or XG interpolation strategy performed significantly better than the original AOD, and they had similar temporal CV among different months or years (Figure S3). The warm season (April-September) generally performed more poorly than the cold season (November-March). The CV result was stable in different years.
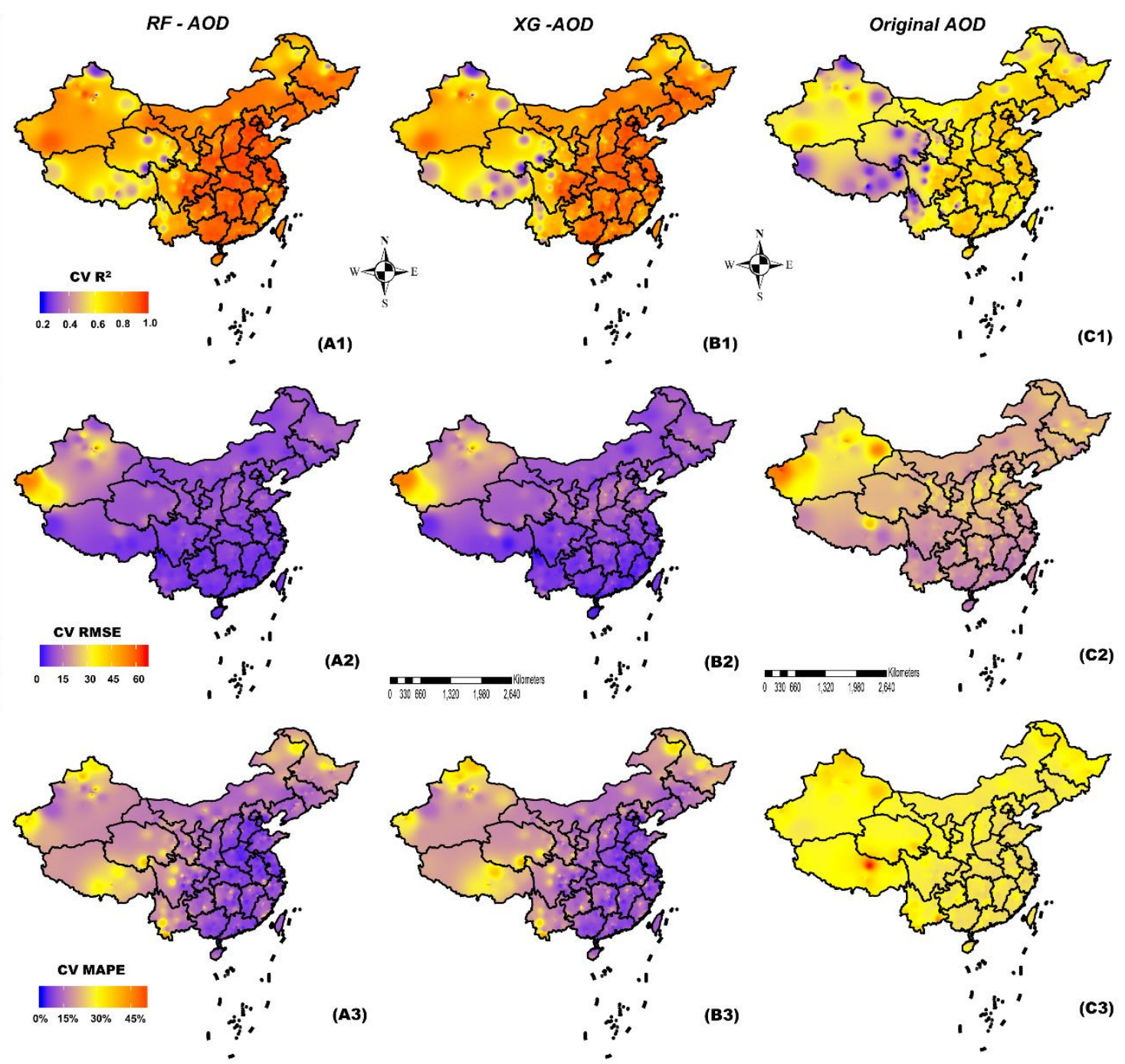

Figure 4. Leave-One-Out-Cross-Validation (LOOCV) performance (CV $\mathrm{R}^{2}$, RMSE and MAPE) of daily $\mathrm{PM}_{2.5}$-prediction models in China using RF-AOD (A1-A3), XG-AOD (B1-B3), and original AOD (C1-C3).

To better clarify the performance of the interpolation methods, we specifically illustrated the result under the worst condition during the study period, i.e., when the coverage of MAIAC AOD was the lowest (4.55\% on 3 July 2018) (Figure 5). The coverage of AOD could reach $96.25 \%$ for both RF- and XG-interpolation (determined by the missing of external information), and median levels of 
interpolated AOD changed from 0.18 to $0.53(\mathrm{RF})$ and to $0.57(\mathrm{XG})$. In the meantime, the coverage of predicted $\mathrm{PM}_{2.5}$ increased from $4.12 \%$ to $95.46 \%$ (determined by the additional missing while considering lag effect), and $\mathrm{LOOCV}_{\text {site }} \mathrm{R}^{2}$ of predicted $\mathrm{PM}_{2.5}$ was 0.70 (original), 0.86 (RF), and 0.85 (XG). The median (IQR) levels of $\mathrm{PM}_{2.5}\left(\mu \mathrm{g} / \mathrm{m}^{3}\right)$, estimated by MAIAC AOD, RF-AOD, and XG-AOD, were 36.34 (22.26), 27.52 (25.68), and 26.32 (27.42), respectively.
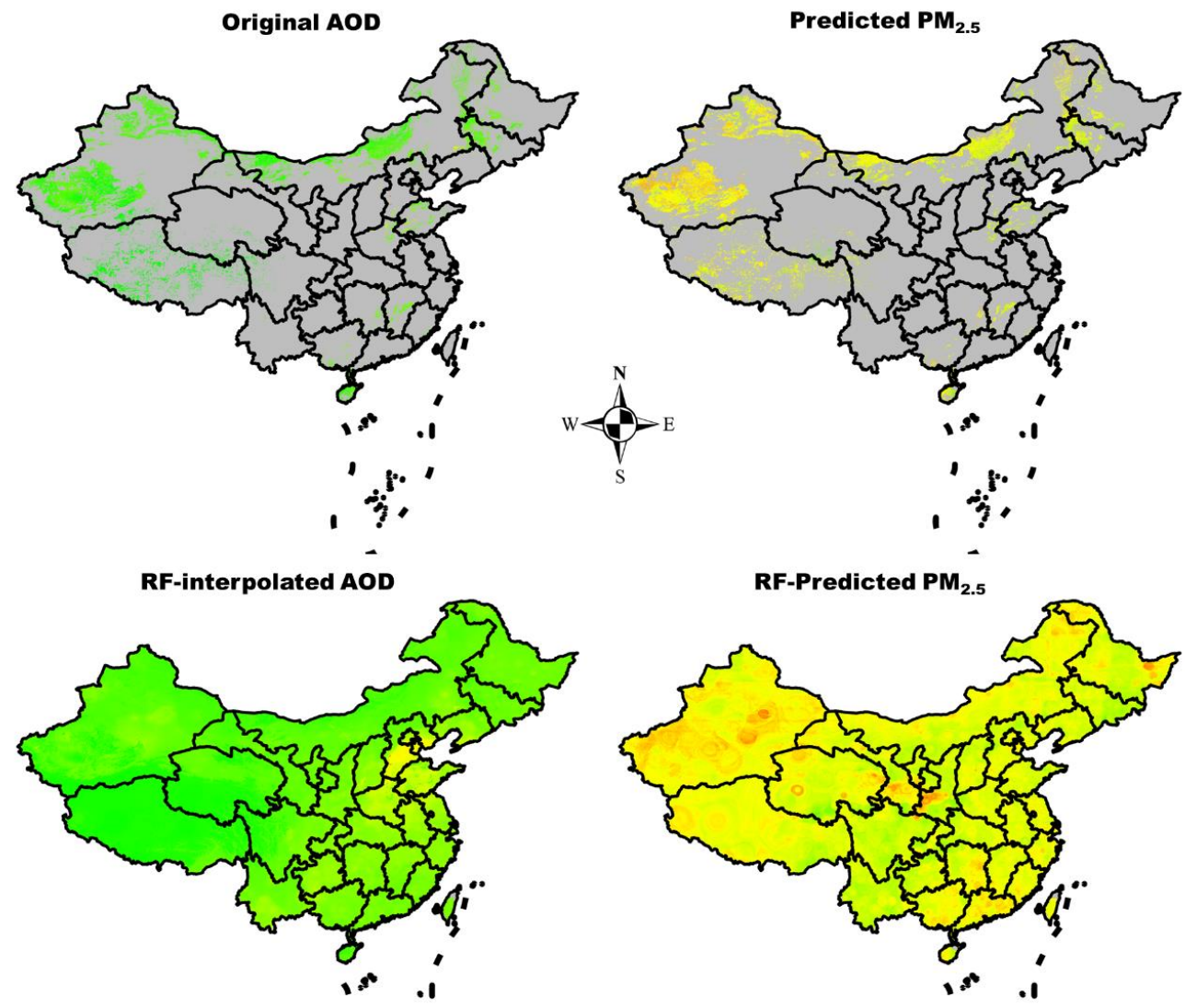

'

'
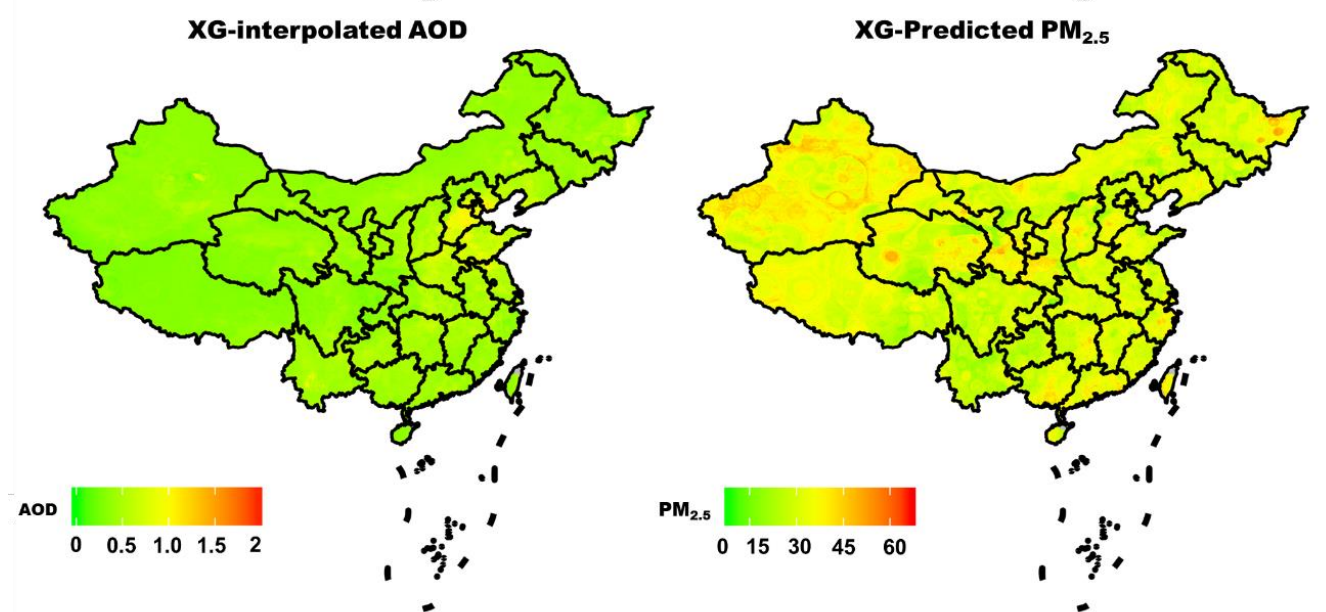

Figure 5. Levels of the observed and interpolated MAIAC AOD, and predicted $\mathrm{PM}_{2.5}$ on 3 July 2018, with the lowest coverage of observed AOD. 


\section{Discussion}

This study developed a series of strategies for estimating daily $\mathrm{PM}_{2.5}$ exposure. This included two stages; the AOD-imputation stage and the $\mathrm{PM}_{2.5}$ predicted stage. For the AOD-imputation stage, and to resolve the difficult aspects of our previous two-step interpolation such as relatively tedious steps and ignoring influences of external information [9], this study compared 12 different algorithms and found ML algorithms (with external information) generally achieved higher coverage than geostatistical algorithms (98.64\% vs. $21.43-87.31 \%$ ). The RF or XG interpolation among ML algorithms also guaranteed a higher interpolated quality $\left(\mathrm{CV} \mathrm{R}^{2}=0.89\right.$ and 0.85$)$ than other ML algorithms (CV $\left.\mathrm{R}^{2}=0.49-0.72\right)$ or geostatistical algorithms $\left(C V R^{2}=0.49-0.78\right)$. However, $X G$ interpolation can better balance the computation time and performance. Compared with the model using original AOD, the $\mathrm{PM}_{2.5}$ prediction model using XG-AOD not only guaranteed higher coverage $(97.83 \%$ vs. $14.35 \%)$, but also a better prediction performance ( $\mathrm{CV} \mathrm{R}^{2}: 0.88$ vs. 0.85$)$ for the $\mathrm{PM}_{2.5}$-prediction stage.

The AOD model has provided optimism for high-coverage estimations of $\mathrm{PM}_{2.5}$ exposure to compensate for the very low coverage of existing ground air quality monitoring sites. It was found, however, that the AOD-missing rate was above $84 \%$ among the day-grid units in China during 2013-2018, and similar problems have been reported in different regions [14,39-41]. This raises debate regarding whether the short-term estimation of $\mathrm{PM}_{2.5}$, based on retrieved AOD data, is more practical for further research rather than data from the sites. For example, in China, $\mathrm{PM}_{2.5}$ predicted by MAIAC AOD still maintains a higher resolution $(1 \mathrm{~km})$ and a higher coverage (approximately 96,534,23 grids) than data from the sites (approximately 1605 sites), and the sites are more likely to be concentrated in eastern China, which is densely populated due to economic and social reasons [40]. A similar situation also exists in many developing countries and in high-income countries [42,43]. Missing observations of MAIAC AOD also tend to be concentrated in specific areas due to uncontrollable factors such as orbit patterns and cloudiness [9,10]. For example, in the lowest coverage day (3 July 2018) during the study period, severe convective weather and heavy rainfall in coastal and central areas of China may have led to such an absence. Furthermore, previous studies have suggested that a monsoon climate is associated with more frequently missed observations. The large seasonal variations in the observed aerosol data $[17,44]$ due to more rainy or cloudy weather in the summer [45], means that regions with a monsoon climate, which are concentrated in densely populated areas, are more susceptible to the missing observation problem and therefore, appropriate AOD interpolation is a prerequisite before using the AOD model for higher-coverage assessments of $\mathrm{PM}_{2.5}$ exposure.

Many attempts have previously been made to impute AOD-missing observations, but it remains unclear which is the most optimal. We compared the performances of 12 approaches, including those proposed here, and found ML algorithms using external information can fill more missing data than geostatistical interpolation (approximately $98.64 \%$ vs. $21.43-87.31 \%$ ). This was consistent with previous assumptions [46-48], but the interpolation quality $\left(\mathrm{CV} \mathrm{R}^{2}: 0.49-0.89\right)$ varied widely in different algorithms, with a similar range (CV R ${ }^{2}$ approximately $\left.0.34-0.85\right)$ reported in previous different studies [14-17,43,46-51]. The higher missing-filled efficiency of ML algorithms indicates that external information can provide more information at the AOD-imputation stage, because the geostatistical interpolation is over-dependent on spatial autocorrelation but ignores other influencing factors on the temporal dimension [21]. Not all ML algorithms, however, can obtain higher interpolation quality than geostatistical interpolation, and the varied interpolation quality suggests that the model structure, or the ability to capture complex spatio-temporal relationships rather than external information, plays a more important role in the accuracy of the AOD-filled process. Therefore, suitable ML algorithms were selected by 10 -fold cross-validation. Most geostatistical interpolations could not provide a fixed model for the entire period, that is, they needed to be developed separately for each map slice at different time points, and so tended to take a longer running time. Among different interpolations, the RF and XG methods were the best two groups, with the highest $C V \mathrm{R}^{2}$ ( 0.89 and 0.85 , respectively), but the time consumption of the RF method was much longer due to parallel operation and different calculation 
methods. Furthermore, the RF method consumed more memory during computation. It is necessary to tradeoff time consumption and interpolation quality if robust computing power is not available.

It was also found that the average AOD levels always rose after interpolation, irrespective of the interpolating method used. This is consistent with the phenomenon that missing more frequently occurs at high MODIS-AOD levels [52,53]. The aerosol hygroscopic growth during missing days results from increased humidity from cloud or humid airflows [54,55]. Another potential reason is that the surface reflectivity, cloudiness, or snow is always associated with over-exposure values $[9,10]$, so it tends to be eliminated during the preprocess of satellite sensors or systems. It was also found that $\mathrm{PM}_{2.5}$ levels on AOD-missing days were lower than those on non-missing days $\left(36.0 \mu \mathrm{g} / \mathrm{m}^{3} \mathrm{vs} .39 .0 \mu \mathrm{g} / \mathrm{m}^{3}\right)$, and this was partially due to shorter particle suspension time with heavy rainfall, convective weather or snow [56], and higher missing rates in the warm season (April-September), with relatively lower $\mathrm{PM}_{2.5}$ levels (Figure 2). This suggests that the relationship between AOD and $\mathrm{PM}_{2.5}$ after AOD interpolation, becomes more complicated than a simple linear relationship [9]. This could explain why AOD interpolation can lead to weaker linear correlations (0.43 to 0.31) (Table S4) but higher accuracy in our $\mathrm{PM}_{2.5}$ prediction model, which can capture the complicated spatio-temporal variations ( 0.85 to 0.88) (Figure 3).

At the $\mathrm{PM}_{2.5}$ predicted stage, further discussion is required regarding how many benefits can be obtained from different interpolated AOD products. Compared with non-AOD model, the imputed AOD always improves the accuracy of $\mathrm{PM}_{2.5}$ estimation $\left(\mathrm{CV} \mathrm{R}{ }^{2}\right.$ PM2.5 estimation $=0.77$ vs. $\left.0.83 \sim 0.88\right)$ (Table S5), especially for XG and RF interpolations which had higher interpolating quality (CV $\mathrm{R}^{2}$ AOD imputation $>0.8$ ). Furthermore, compared with RF-AOD and XG-AOD, the satellite $\mathrm{PM}_{2.5}$ model using original AOD performed relatively poorly in spatial and temporal CVs (spatial (temporal) CV $\mathrm{R}^{2}=0.83(0.83)$ vs. $0.82(0.82)$ vs. $\left.0.65(0.61)\right)$. The lower LOOCV $\mathrm{R}^{2}(=0.56)$ when only using original AOD further proved its poorer spatial application to all mainland China because different missing rates in different grids can increase the heterogeneity (or uncertainty) of predictions, and further weaken spatial extrapolation to other grids. Furthermore, incomplete time series of AOD produced for each grid also makes it more difficult to obtain an accurate prediction in any out-of-sample time. Compared with the XG method, however, the higher accuracy of RF methods at the AOD-imputation stage did not bring more benefits to the $\mathrm{PM}_{2.5}$-prediction stage. It indicated that the missing rate of the AOD product, compared with the accuracy of the interpolated AOD product, is the key to spatial and temporal extrapolation of the $\mathrm{PM}_{2.5}$-prediction stage.

Some limitations were present in this study. First, the complex relationships between AOD-missing effect and $\mathrm{PM}_{2.5}$ may cause annual and regional differences, which need to be further analyzed in more countries for a longer research period. Second, the AOD miss-filling approaches taken here are based on using known predictors which are easily accessed and are frequently recorded in most areas and therefore, some other chemical or physical features such as chemical composition in aerosol and sun radiation were not considered in this study. Finally, the LOOCV result for all of China was interpolated by UK, and therefore, some unavoidable bias due to the UK technique may be present. This result provides an approximate assessment only for spatial dimensions.

\section{Conclusions}

This study proposed a XGBoost method to impute missing data of AOD based on some external predictors. By comparing a variety of different imputation methods, XGBoost is confirmed to be a less consuming-time choice, with almost full coverage, good missing-imputation quality, and consequently, accurate prediction of $\mathrm{PM}_{2.5}$. In terms of practicality, our study provides some guidance, strategies, and a tempo-spatially continuous $\mathrm{PM}_{2.5}$ dataset for future short-term health impact assessments in epidemiological studies of air pollution.

Supplementary Materials: The following are available online at http:/www.mdpi.com/2072-4292/12/18/3008/s1, Figure S1. Geographical distribution of $\mathrm{PM}_{2.5}$ monitoring sites (A) and meteorological stations (B) in mainland China in 2015. Figure S2. Geographical locations of regions and provinces in China. Figure S3. The temporal 
CV performance (Proportion of sites with different $\mathrm{CV} \mathrm{R}^{2}$ ) of daily Satellite-PM $\mathrm{PM}_{2.5}$ model in China with RF-AOD, XG-AOD and Original AOD. Table S1. The optimal parameters selected in AOD-filled Stage and PM $\mathrm{PM}_{2.5}$ Predicted Stage. Table S2. Optimal combination of variables selected in different regions of China. Table S3. The spatial and temporal CV of Geostatistical and ML interpolation for MAIAC AOD product. The comparison of daily Satellite-PM $\mathrm{PM}_{2.5}$ model with AOD products interpolated by using interpolating methods (with $\mathrm{CV}^{2}$ for interpolation $>=0.7$ ). Table S6. The spatial and temporal CV of using different interpolated-AOD product in $\mathrm{PM}_{2.5}$ Predicted Stage.

Author Contributions: Conceptualization, Z.-Y.C., J.-Q.J., R.Z., T.-H.Z., J.-J.C., J.Y., C.-Q.O. and Y.G.; Data curation, Z.-Y.C., J.-Q.J., J.-J.C. and J.Y.; Formal analysis, Z.-Y.C.; Funding acquisition, C.-Q.O. and Y.G.; Methodology, Z.-Y.C., R.Z. and C.-Q.O.; Project administration, Z.-Y.C., C.-Q.O. and Y.G.; Software, Z.-Y.C.; Supervision, C.-Q.O. and Y.G.; Validation, Z.-Y.C., J.-Q.J., R.Z. and T.-H.Z.; Writing-original draft, Z.-Y.C.; Writing-review and editing, Z.-Y.C., C.-Q.O. and Y.G. All authors have read and agreed to the published version of the manuscript.

Funding: This research was funded by National Nature Science Foundation of China [81573249], Nature Science Foundation of Guangdong Province [2016A030313530] and Australian National Health and Medical Research Council [APP1107107]. And The APC was funded by National Nature Science Foundation of China [81573249] and Nature Science Foundation of Guangdong Province [2016A030313530].

Acknowledgments: This study was supported by National Nature Science Foundation of China [81573249], Nature Science Foundation of Guangdong Province [2016A030313530]. YG was supported by Career Development Fellowship of Australian National Health and Medical Research Council [APP1107107].

Conflicts of Interest: The authors declare no conflict of interest.

\section{References}

1. International Energy Agency. Key World Energy Statistics 2018; OECD Publishing: Paris, France, 2018.

2. Cohen, A.J.; Brauer, M.; Burnett, R.; Anderson, H.R.; Frostad, J.; Estep, K.; Balakrishnan, K.; Brunekreef, B.; Dandona, L.; Dandona, R.; et al. Estimates and 25-year trends of the global burden of disease attributable to ambient air pollution: An analysis of data from the Global Burden of Diseases Study 2015. Lancet 2017, 389, 1907-1918. [CrossRef]

3. Lee, S.; Lee, W.; Kim, D.; Kim, E.; Myung, W.; Kim, S.-Y.; Kim, H. Short-term PM 2.5 exposure and emergency hospital admissions for mental disease. Environ. Res. 2019, 171, 313-320. [CrossRef]

4. Shah, A.S.V.; Lee, K.K.; McAllister, D.A.; Hunter, A.; Nair, H.; Whiteley, W.; Langrish, J.P.; Newby, D.E.; Mills, N.L. Short term exposure to air pollution and stroke: Systematic review and meta-analysis. BMJ 2015, 350, h1295. [CrossRef] [PubMed]

5. Guaita, R.; Pichiule, M.; Maté, T.; Linares, C.; Díaz, J. Short-term impact of particulate matter $\left(\mathrm{PM}_{2.5}\right)$ on respiratory mortality in Madrid. Int. J. Environ. Health Res. 2011, 21, 260-274. [CrossRef] [PubMed]

6. Kloog, I.; Ridgway, B.; Koutrakis, P.; Coull, B.A.; Schwartz, J.D. Long-and short-term exposure to $\mathrm{PM}_{2.5}$ and mortality: Using novel exposure models. Epidemiology 2013, 24, 555. [CrossRef] [PubMed]

7. Mar, T.F.; Jansen, K.; Shepherd, K.; Lumley, T.; Larson, T.V.; Koenig, J.Q. Exhaled nitric oxide in children with asthma and short-term $\mathrm{PM}_{2.5}$ exposure in Seattle. Environ. Health Perspect. 2005, 113, 1791-1794. [CrossRef]

8. WHO. Air Quality Deteriorating in Many of the World's Cities; WHO: Geneva, Switzerland, 2014.

9. Chen, Z.-Y.; Zhang, T.-H.; Zhang, R.; Zhu, Z.-M.; Yang, J.; Chen, P.-Y.; Ou, C.-Q.; Guo, Y. Extreme gradient boosting model to estimate $\mathrm{PM}_{2.5}$ concentrations with missing-filled satellite data in China. Atmos. Environ. 2019, 202, 180-189. [CrossRef]

10. Kahn, R.A.; Nelson, D.L.; Garay, M.J.; Levy, R.C.; Bull, M.A.; Diner, D.J.; Martonchik, J.V.; Paradise, S.R.; Hansen, E.G.; Remer, L.A. MISR aerosol product attributes and statistical comparisons with MODIS. IEEE Trans. Geosci. Remote Sens. 2009, 47, 4095-4114. [CrossRef]

11. Paciorek, C.J.; Liu, Y. Limitations of remotely sensed aerosol as a spatial proxy for fine particulate matter. Environ. Health Perspect. 2009, 117, 904-909. [CrossRef]

12. Zhang, T.; Gong, W.; Zhu, Z.; Sun, K.; Huang, Y.; Ji, Y. Semi-physical estimates of national-scale PM10 concentrations in China using a satellite-based geographically weighted regression model. Atmosphere 2016, 7,88. [CrossRef] 
13. Liu, Y.; Paciorek, C.J.; Koutrakis, P. Estimating regional spatial and temporal variability of $\mathrm{PM}_{2.5}$ concentrations using satellite data, meteorology, and land use information. Environ. Health Perspect. 2009, 117, 886. [CrossRef] [PubMed]

14. Chen, Z.; Zhang, T.; Zhang, R.; Zhu, Z.; Ou, C.; Guo, Y. Estimating $\mathrm{PM}_{2.5}$ concentrations based on non-linear exposure-lag-response associations with aerosol optical depth and meteorological measures. Atmos. Environ. 2018, 173, 30-37. [CrossRef]

15. Kloog, I.; Koutrakis, P.; Coull, B.A.; Lee, H.J.; Schwartz, J. Assessing temporally and spatially resolved PM 2.5 exposures for epidemiological studies using satellite aerosol optical depth measurements. Atmos. Environ. 2011, 45, 6267-6275. [CrossRef]

16. Lv, B.; Hu, Y.; Chang, H.H.; Russell, A.G.; Bai, Y. Improving the accuracy of daily $\mathrm{PM}_{2.5}$ distributions derived from the fusion of ground-level measurements with aerosol optical depth observations, a case study in North China. Environ. Sci. Technol. 2016, 50, 4752. [CrossRef]

17. Xiao, Q.Y.; Wang, Y.; Howard, H.C.; Xia, M.; Geng, G. Full-coverage high-resolution daily PM $_{2.5}$ estimation using MAIAC AOD in the Yangtze River Delta of China. Remote Sens. Environ. 2017, 199, 437-446. [CrossRef]

18. Di, Q.; Kloog, I.; Koutrakis, P.; Lyapustin, A.; Wang, Y.; Schwartz, J. Assessing PM 2.5 exposures with high spatiotemporal resolution across the continental United States. Environ. Sci. Technol. 2016, 50, 4712-4721. [CrossRef]

19. Lyapustin, A.; Wang, Y.; Laszlo, I.; Kahn, R.; Korkin, S.; Remer, L.; Levy, R.; Reid, J. Multiangle implementation of atmospheric correction (MAIAC): 2. Aerosol algorithm. J. Geophys. Res. 2011, 116. [CrossRef]

20. Lyapustin, A.; Wang, Y.; Korkin, S.; Huang, D. MODIS Collection 6 MAIAC algorithm. Atmos. Meas. Tech. 2018, 11, 5741-5765. [CrossRef]

21. Li, L.; Franklin, M.; Girguis, M.; Lurmann, F.; Wu, J.; Pavlovic, N.; Breton, C.; Gilliland, F.; Habre, R. Spatiotemporal imputation of MAIAC AOD using deep learning with downscaling. Remote Sens. Environ. 2020, 237, 111584. [CrossRef]

22. Zhang, Z.; Wu, W.; Fan, M.; Wei, J.; Tan, Y.; Wang, Q. Evaluation of MAIAC aerosol retrievals over China. Atmos. Environ. 2019, 202, 8-16. [CrossRef]

23. Hu, X.; Waller, L.A.; Lyapustin, A.; Wang, Y.; Al-Hamdan, M.Z.; Crosson, W.L.; Estes, M.G., Jr.; Estes, S.M.; Quattrochi, D.A.; Puttaswamy, S.J. Estimating ground-level $\mathrm{PM}_{2.5}$ concentrations in the Southeastern United States using MAIAC AOD retrievals and a two-stage model. Remote Sens. Environ. 2014, 140, 220-232. [CrossRef]

24. CHINA MEE. Ambient Air Quality Standardss.GB 3095-2012; China Environmental: Beijing, China, 2016.

25. San Martini, F.M.; Hasenkopf, C.A.; Roberts, D.C. Statistical analysis of $\mathrm{PM}_{2.5}$ observations from diplomatic facilities in China. Atmos. Environ. 2015, 110, 174-185. [CrossRef]

26. Lv, B.; Hu, Y.; Chang, H.H.; Russell, A.G.; Cai, J.; Xu, B.; Bai, Y. Daily estimation of ground-level $\mathrm{PM}_{2.5}$ concentrations at $4 \mathrm{~km}$ resolution over Beijing-Tianjin-Hebei by fusing MODIS AOD and ground observations. Sci. Total Environ. 2017, 580, 235-244. [CrossRef] [PubMed]

27. Zhu, X.; Liu, D.; Chen, J. A new geostatistical approach for filling gaps in Landsat ETM+ SLC-off images. Remote Sens. Environ. 2012, 124, 49-60. [CrossRef]

28. Wikle, C.; Zammit-Mangion, A.; Cressie, N. Spatio-Temporal Statistics with R; CRC Press: Boca Raton, FL, USA, 2019; ISBN 9781351769723.

29. Liaw, A.; Wiener, M. Classification and regression by RandomForest. $R$ News 2002, 2, 18-22.

30. Chen, T.; Guestrin, C. XGBoost: A scalable tree boosting system. Knowl. Discov. Data Min. 2016, 785-794. [CrossRef]

31. Wang, L. Support Vector Machines: Theory and Applications; Springer Science \& Business Media: Berlin/Heidelberg, Germany, 2005; Volume 177, p. 3887.

32. Ridgeway, G. Generalized Boosted Models: A guide to the gbm package. Update 2007, 1, 2007.

33. Brenning, A. Statistical geocomputing combining R and SAGA: The example of landslide susceptibility analysis with generalized additive models. Hamburg. Beiträge zur Phys. Geogr. und Landschaftsökologie 2008, 19,410 . 
34. Pérez-Rodríguez, P.; Gianola, D.; Weigel, K.A.; Rosa, G.J.M.; Crossa, J. An R package for fitting Bayesian regularized neural networks with applications in animal breeding. J. Anim. Sci. 2013, 91, 3522-3531. [CrossRef]

35. Kuhn, M. Building predictive models in R using the caret package. J. Stat. Softw. 2008, 28, 1-26. [CrossRef]

36. Just, A.C.; De Carli, M.M.; Shtein, A.; Dorman, M.; Lyapustin, A.; Kloog, I. Correcting measurement error in satellite aerosol optical depth with machine learning for modeling $\mathrm{PM}_{2.5}$ in the Northeastern USA. Remote Sens. 2018, 10, 803. [CrossRef] [PubMed]

37. He, Q.; Huang, B. Satellite-based mapping of daily high-resolution ground $\mathrm{PM}_{2.5}$ in China via space-time regression modeling. Remote Sens. Environ. 2018, 206, 72-83. [CrossRef]

38. Xue, T.; Zheng, Y.; Geng, G.; Zheng, B.; Jiang, X.; Zhang, Q.; He, K. Fusing observational, satellite remote sensing and air quality model simulated data to estimate spatiotemporal variations of $\mathrm{PM}_{2.5}$ exposure in China. Remote Sens. 2017, 9, 221. [CrossRef]

39. Belle, J.; Liu, Y. Evaluation of Aqua MODIS Collection 6 AOD parameters for air quality research over the Continental United States. Remote Sens. 2016, 8, 815. [CrossRef]

40. You, W.; Zang, Z.; Zhang, L.; Li, Y.; Pan, X.; Wang, W. National-scale estimates of ground-level $\mathrm{PM}_{2.5}$ concentration in China using geographically weighted regression based on $3 \mathrm{~km}$ resolution MODIS AOD. Remote Sens. 2016, 8, 184. [CrossRef]

41. Zhang, T.; Gong, W.; Wang, W.; Ji, Y.; Zhu, Z.; Huang, Y. Ground Level $\mathrm{PM}_{2.5}$ Estimates over China Using Satellite-Based Geographically Weighted Regression (GWR) Models Are Improved by Including NO2 and Enhanced Vegetation Index (EVI). Int. J. Environ. Res. Public Health 2016, 13, 1215. [CrossRef]

42. Kim, M.; Zhang, X.; Holt, J.B.; Liu, Y. Spatio-Temporal Variations in the Associations between Hourly $\mathrm{PM}_{2.5}$ and Aerosol Optical Depth (AOD) from MODIS Sensors on Terra and Aqua. Health 2013, 5, 8-13. [CrossRef]

43. McGuinn, L.; Schneider, A.E.; Ward-Caviness, C.; Di, Q.; Schwartz, J.D.; Russell, A.; Hauser, E.; Kraus, W.; Neas, L.; Cascio, W. Comparison of Long-Term $\mathrm{PM}_{2.5}$ Concentrations from Ground-Based Monitoring, CMAQ Models and Satellite-Derived AOD to Characterize Adverse Cardiovascular Outcomes. In ISEE Conference Abstracts; Environmental Health Perspectives: Ottawa, Canada, 2018; Volume 2018.

44. Liu, X.; Yan, L.; Yang, P.; Yin, Z.-Y.; North, G.R. Influence of Indian summer monsoon on aerosol loading in East Asia. J. Appl. Meteorol. Climatol. 2011, 50, 523-533. [CrossRef]

45. Li, Z.; Lau, W.; Ramanathan, V.; Wu, G.; Ding, Y.; Manoj, M.G.; Liu, J.; Qian, Y.; Li, J.; Zhou, T. Aerosol and monsoon climate interactions over Asia. Rev. Geophys. 2016, 54, 866-929. [CrossRef]

46. Zhang, R.; Di, B.; Luo, Y.; Deng, X.; Grieneisen, M.L.; Wang, Z.; Yao, G.; Zhan, Y. A nonparametric approach to filling gaps in satellite-retrieved aerosol optical depth for estimating ambient $\mathrm{PM}_{2.5}$ levels. Environ. Pollut. 2018, 243, 998-1007. [CrossRef]

47. Yang, J.; Hu, M. Filling the missing data gaps of daily MODIS AOD using spatiotemporal interpolation. Sci. Total Environ. 2018, 633, 677. [CrossRef] [PubMed]

48. Goldberg, D.L.; Gupta, P.; Wang, K.; Jena, C.; Zhang, Y.; Lu, Z.; Streets, D.G. Using gap-filled MAIAC AOD and WRF-Chem to estimate daily $\mathrm{PM}_{2.5}$ concentrations at $1 \mathrm{~km}$ resolution in the Eastern United States. Atmos. Environ. 2019, 199, 443-452. [CrossRef]

49. Sorek-Hamer, M.; Strawa, A.W.; Chatfield, R.B.; Esswein, R.; Cohen, A.; Broday, D.M. Improved retrieval of $\mathrm{PM}_{2.5}$ from satellite data products using non-linear methods. Environ. Pollut. 2013, 182, 417-423. [CrossRef] [PubMed]

50. Geng, G.; Zhang, Q.; Martin, R.V.; van Donkelaar, A.; Huo, H.; Che, H.; Lin, J.; He, K. Estimating long-term $\mathrm{PM}_{2.5}$ concentrations in China using satellite-based aerosol optical depth and a chemical transport model. Remote Sens. Environ. 2015, 166, 262-270. [CrossRef]

51. Liu, Y.; He, K.; Li, S.; Wang, Z.; Christiani, D.C.; Koutrakis, P. A statistical model to evaluate the effectiveness of $\mathrm{PM}_{2.5}$ emissions control during the Beijing 2008 Olympic Games. Environ. Int. 2012, 44, 100-105. [CrossRef]

52. He, Q.; Li, C.; Tang, X.; Li, H.; Geng, F.; Wu, Y. Validation of MODIS derived aerosol optical depth over the Yangtze River Delta in China. Remote Sens. Environ. 2010, 114, 1649-1661. [CrossRef]

53. Zhang, T.; Zhu, Z.; Gong, W.; Zhu, Z.; Sun, K.; Wang, L.; Huang, Y.; Mao, F.; Shen, H.; Li, Z. Estimation of ultrahigh resolution $\mathrm{PM}_{2.5}$ concentrations in urban areas using $160 \mathrm{~m}$ Gaofen-1 AOD retrievals. Remote Sens. Environ. 2018, 216, 91-104. [CrossRef] 
54. Na, K.; Kumar, K.R.; Yan, Y.; Diao, Y.; Yu, X. Correlation Analysis between AOD and Cloud Parameters to Study Their Relationship over China Using MODIS Data (2003-2013): Impact on Cloud Formation and Climate Change. Aerosol Air Qual. Res. 2014, 15, 958-973.

55. Bi, J.; Belle, J.H.; Wang, Y.; Lyapustin, A.I.; Wildani, A.; Liu, Y. Impacts of snow and cloud covers on satellite-derived $\mathrm{PM}_{2.5}$ levels. Remote Sens. Environ. 2019, 221, 665-674. [CrossRef]

56. Feng, X.; Wang, S. Influence of different weather events on concentrations of particulate matter with different sizes in Lanzhou, China. J. Environ. Sci. 2012, 24, 665-674. [CrossRef]

(C) 2020 by the authors. Licensee MDPI, Basel, Switzerland. This article is an open access article distributed under the terms and conditions of the Creative Commons Attribution (CC BY) license (http://creativecommons.org/licenses/by/4.0/). 